Science HQ 750

. A 1

L7

3

Science HQ 750.A1 L7 3

Elderton, Ethel Mary.

The relative strength of nurture and nature 


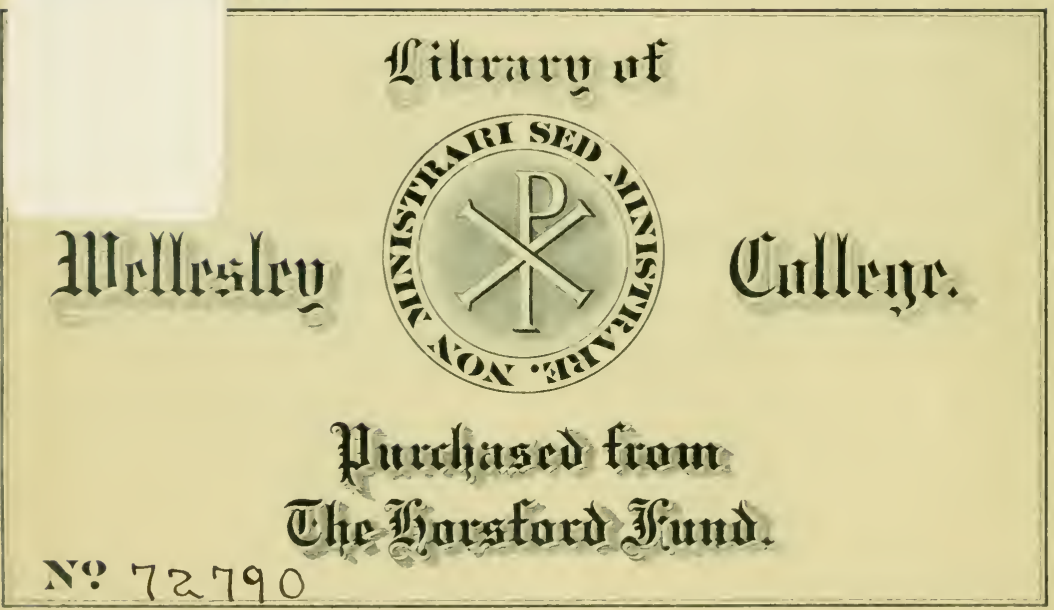




UNIVERSITY OF LONDON

GALTON LABORATORY FOR NATIONAL EUGENICS

EUGENICS LABORATORY LECTURE SERIES. III.

The Relative Strength of Nurture and Nature

\author{
BY \\ ETHEL M. ELDERTON, \\ GALTON RESEARCH SCHOLAR
}

\title{
LONDON
}

DULAU AND CO., 37, SOHO SQUARE, W.

1909

Price One Shilling 


\section{UNIVERSITY OF LONDON}

\section{The Francis Galton Eugenics Laboratory}

UNIVERSITY COLLEGE, GOWER STREET, W.C.

The Laboratory is under the supervision of Professor KARL Pearson, F.R.S., in consultation with Sir Francis Galton, F.R.S. Galton Research Fellow: David Heron, M.A. Galton Research Scholar: Ethel M. Elderton. Computer: Amy Barrington.

National Eugenics is the study of agencies under social control, that may improve or impair the racial qualities of fulure generations, either physically or mentully.

It is the intention of the Founder, that the Laboratory shall serve (i) as a storehouse of statistical material bearing on the mental and physical conditions in man, and the relation of these conditions to inheritance and environment; (ii) as a centre for the publication or other form of distribution of information concerning National Eugenics; (iii) as a school for training and assisting research-workers in special problems in Eugenics.

Short courses are provided for those who are engaged in social, medical, or anthropometric work.

EUGENICS LABORATORY LECTURE SERIES.

Published by Duluu and Co., 37, Soho Square, W.

I. The Scope and Importance to the State of the Science of National Eugenics. By KarL Pearson, F.R.S. Issued. Price is.

II. The Groundwork of Eugenics. By KarL Pearson, F.R.S. Issued. Price is.

III. The Relative Strength of Nurture and Nature. By Ethel M. Elderton. Issued. Price is.

IV. On the Marriage of First Cousins. By Ethel M. Elderton. [Nearly ready.

V. The Problem of Practical Eugenics. By Karl Pearson, F.R.S. Issued. Price is. 


\title{
The Relative Strength of Nurture and Nature
}

BY

\author{
ETHEL M. ELDERTON \\ GALTON RESEARCH SCHOLAR
}

\author{
LONDON \\ PUBLISHED BY DULAU AND CO. \\ 37, SOHO SQUARE, W.




\section{0 \\ PREFATORY NOTE.}

ThIS Lecture gives results drawn from three memoirs (a) The Infuence of Parental Occupation and Habit on the Welfare of the Offspring, by Ethel M. Elderton, (b) The Influence of Unfavourable Home Environment and Defective Physique on the Intelligence of School Children, by David Heron, and (c) A First Study of the Inheritance of Vision and of the Relative Infuence of Heredity and Environment on Sight, by Amy Barrington and Karl Pearson. The latter has been recently published and the two former will shortly appear in the Eugenics Laboratory Memoir Series. For further details and discussion of results the reader is referred to the above memoirs. 


\section{THE RELATIVE STRENGTH OF NURTURE AND NATURE 1 .}

When we approach the fundamental problems of human life, and endeavour to study the causes which make for the physical and mental fitness of a nation, we are at once struck by the vast network of associated factors, which render so complex any attempt at a solution of the simplest problem in the relationship of nurture and environment to human progress.

We might for example discover that the mentally and physically fitter child comes from the cleaner and less crowded home, and therefore argue that the spread of such homes is a condition for national progress. But further investigation might show that the essential condition for such homes is the existence of mentally and physically fit parents, and that the fitness of the children flows after all from the parentage and not from the home.

Or again if we take the problem of employment of mothers, we might discover that employed mothers have the healthier children, and we might on this ground oppose any attempt to restrict the factory work of women during childbearing years. But on

${ }^{1}$ This paper was delivered as the seventh of a course of Eight Lectures on National Eugenics at the Galton Laboratory 1909. 
further investigation we might ascertain that such mothers are, on the average older and have older children, from whom time has weeded the weaklings, and that the problem cannot be solved by the simple question of the physique of the children of employed and unemployed mothers, without regard to the age distribution of the children.

Once more it is conceivable that we might find that the deathrate of innkeepers much in excess of the deathrate of the clergy, and overlook the fact that the average age at starting the occupation of innkeeper is far higher than that of entering the church, because ultimately to keep an inn is the ambition of men, who begin life in a variety of other callings. As a last illustration we may take the problem of the effect of the drinking of the father on the health and ability of the offspring. We might find that the father who drinks had abler and physically better developed sons than the non-drinker. Yet on closer investigation it might appear (i) that on the average the drinker was the abler workman, and thus the apparently greater ability of the offspring was really an hereditary matter, (ii) that the abler workman got higher wages, and thus, notwithstanding the drink, the food at home, especially perhaps in the earlier days of the family life, had been ampler and of better quality. There is hardly a single problem of parental occupation and habit, of home environment and school influence which is not of the greatest complexity, and full of pitfalls for even the most cautious statistician. And if this be true, what must be said for the philanthropist and 
social reformer who without hesitation preach that social salvation lies in this or that line of conduct? What must be our judgment of the "practical man" and the statesman who legislate in the direction indicated by the falling scale of popular opinion, without any real examination of the intense complexity, the subtle biological effects of even slight changes, in the factors on which our national weal depends?

A factory act may be carried owing to a wave of popular emotion, which paints the horrors of child-labour in the mills. Twenty years afterwards it may become apparent that children were taken care of because their labour was of value, but that their value depending on their labour, they are, since the act, an unmarketable commodity and have ceased to be born on this very account ${ }^{1}$.

What guide can we take to indicate the path of true social reform through such a tangle of cause and effect as we find involving the relative influence of nature and nurture on human life? It is not enough to show that results are associated with this or that factor; we have a vast complex of associated factors, and out of this complex we have in some way to pick out the more important and in a certain sense the fundamental factors. The only effective method by which at present it seems possible to approach such a problem is that of correlation ${ }^{2}$. Taking the social ${ }^{1}$ For a fuller discussion of this point see Pearson: The Problem of Practical Eugenics, Eugenics Laboratory Lecture Series V.

2 The coefficient of correlation measures the amount of resemblance or association between characteristics of individuals or of things; it is represented by a decimal which lies between $o$ and I. As the correlation coefficient rises to I we approach a condition of absolute dependence. As it falls to $o$ we approach a condition of absolute independence. Thus 
conditions we wish to modify, we must study their correlation with as many factors as we can possibly measure. In the choice of these factors we must of course be guided by the reasonable probability of association and by the limits of human life and energy. The correlations of a multiplicity of factors being known we may justifiably assume that the factors with the highest correlations are, among those dealt with by us, the most important, and then the process of "partial correlation" will guide us still further towards a final judgment of what fundamentally are social cause and effect.

We admit to the full that even then we may not have avoided all danger of pitfalls, that we may have overlooked possible factors, and that spurious correlation may have arisen from all sorts of disregarded selective processes. The prudent statistician will always advance his conclusions with a word of caution; he will simply state that they are those which reasonably follow from the data provided. But at the same time he will not hesitate to proclaim that in the present state of our knowledge the calculus of correlation is the sole rational and effective method available for attacking these urgent social problems. If that calculus throws no light, when properly applied, on social dynamics, then the only solution is to develop a finer statistical calculus; no other instrument, least of all general reasoning with appeal to social or moral prejudgments, can at present aid

the correlation between right and left femur in man is 96 which is practically unity, i.e. almost perfect dependence as we should expect. The inheritance between stature of father and son is .5I, half-way between absolute dependence and absolute independence. 
us in our difficulties with regard to what makes for, and what mars national fitness. Indeed we venture to go further and to assert that much of the canon of social conduct and moral action as it has existed in the past and as it widely exists at the present will be found inadequate or even antisocial, when we understand more fully the manner in which legislation, social custom, and philanthropy (in the old sense) tend to modify the biological factors on which human progress so largely has depended.

There is no one having any biological knowledge who would refuse to admit the enormous part played by environment in modifying living forms. This modification, however, is of two kinds:

(a) A change in the somatic characters of the individual following upon his transfer to different surroundings or his treatment to different conditions of nurture; this environmental change in the individual appears to be more marked in plants than in animals. If it is in any case persistent after the offspring of the individual have returned to the original environment, most biologists would assert that a germinal change of some kind, an unrecognized selection of germ plasm, has taken place in the original individual.

(b) A change in the germ characters of the race, owing to the environment selecting for survival a certain differential class of individuals, and their somatic characters thus becoming more frequent and possibly dominant in the population owing to the strength of heredity.

Now we are not in any way concerned with a 
consideration of this second modification due to environment. We have solely to deal with the problem of the extent to which the offspring are modified by an indirect environmental factor, namely the occupations and habits of their parents and the condition of their homes. We are not considering (b), for we are dealing with surviving children, and not with the selective infantile deathrate. Now the influence of the parental environmental factor on the welfare of children is of fundamental importance, quite apart from the selective infantile deathrate and the possibility of the inheritance of acquired characters. It is at present and has been in the past the chief direction of legislative and philanthropic attack on social evils. Degeneracy of every form has been attributed to poverty, bad housing, unhealthy trades, drinking, industrial occupation of women, and other direct or indirect environmental influences on offspring. If we could by education, by legislation, or by social effort change the environmental conditions, would the race at once rise to a markedly higher standard of physique and mentality? Much, if not the whole battle for social reform has been based on the assumption that this question was obviously to be answered in the affirmative. No direct investigation has really ever been made of the intensity of the influence of environment on man. To modify the obviously repellent was the immediate instinct of the more gently nurtured and controlling social class. Was this direction of social reform really capable of effecting any substantial change? Nay by lessening the selective deathrate 
may it not have contributed to emphasizing the very evils it was intended to lessen? These are the problems which occur to the eugenist and call for investigation and if possible settlement.

The outlines of our enquiry are not hard to sum up. We know from a variety of investigations that the correlation between physical and mental characters in parent and offspring is about 45 to 50. The first question to be asked is: Are the physical and mental characters of children correlated with their or their parents' environment to a higher, an equal, or a lesser extent? But even the determination of this first question will not finally solve the relative intensity of the environmental and heredity factors. We have still to ask how far the parents' physical and mental characters are productive of the observed environment. It is conceivable that the relation between children's physique, for example, and parental occupation is an indirect result of the inheritance of physique and a correlation between parents' physique and their occupation. In other words, what we are attributing to environment may be a secondary influence of heredity itself. A weakling may have no option but to follow an unhealthy trade, a man is a tailor or shoemaker, because he has not the physique for smith or navvy. His offspring may be physically inferior because he is a weakling and not because he follows an unhealthy trade. Clearly, to solve our problem, we must know if there be any correlation between the same character in the parent as we are observing in the child and the environment we are 
correlating with the child's character. Unfortunately data enabling us to determine the relationship of any mental or physical character of the parent with the environment which is supposed to influence the child is rarely forthcoming. We have, however, some information which may help us indirectly in our consideration of this part of the enquiry.

After this preliminary warning as to the difficulties of the problem of heredity and environment I propose to consider what evidence is available for determining the relative intensity of nature and nurture in the case of man. The material at my disposal may be summed up as follows:

I. The Report on the Physical Condition of fourteen hundred school children in the City of Edinburgh, with some account of their homes and surroundings, issued by the Charity Organization Society. Information is given as to the number of children, living and dead, the number of rooms, rent, father's work and wages, mother's work, work and wages of other members of the family, and age, height, weight, intelligence, condition of teeth, eyes, ears, nose and throat of the school children, and an account of the home in each case; information is given as to the drinking of the parents, cleanliness of the home, morality of the parents, \&c.

In this splendid piece of research school teachers, doctors, and workers belonging to the C.O.S. have combined; information has been sought from many sources and infinite pains must have been taken. It is a pleasure to work from such a report, but one longs at the same time that the numbers were ten 
times as great, and that the C.O.S. might obtain a far larger band of workers who would investigate in like manner the condition of fourteen thousand instead of fourteen hundred school children in Great Britain. The machinery now exists for the medical examination of school children, but from the point of view of the eugenist it will be of comparatively little value for measuring the effects of environment unless the children are followed into their homes, and information is collected and recorded as has been done by the C.O.S. in Edinburgh.

II. A Record of Measurements \&c. for 1905 of children attending the public schools in Glasgow, lent to us by the Scottish Education Department. We have from this source information about 72,857 school children; among other facts recorded are the age, height, weight, occupation of the father and employment of the mother.

III. An account of the children in the special schools in Manchester, kindly provided for us by Miss Dendy. Among other information the health and intelligence of the brothers and sisters of the defective child under consideration are given, and the drinking and health of the parents.

The main points to which we have turned our attention up to the present time are:

(I) The influence of the employment of mothers on the physique of their children.

(2) The influence of the occupation of the father on the physique of the children.

(3) The influence of drink in the parents on the 
height, weight, general health and intelligence of the children.

(4) The influence of overcrowding, bad economic condition of the home, moral and physical condition of the parents on the intelligence, eyesight, glands, and hearing of the children.

In our investigation of the first and third points we are fortunate enough to possess two distinct sets of statistics in each case, so I feel I can speak with greater confidence of the results.

In the other two cases we are dependent on one set of statistics in each case, for the influence of the occupation of the father we have the Glasgow School Board statistics, and for the effect of environment on intelligence, eyesight, \&c. we have the Report of the Edinburgh C.O.S.

I am glad to say that during the last few weeks a fresh set of statistics dealing with Edinburgh children has been lent to the Laboratory by Dr Leslie Mackenzie, which contains much of interest, and a further set of schedules from Professor Matthew Hay dealing with Aberdeen children.

First I will examine the results we have found for the correlation between the employment of mothers and the height and weight of their sons; and I would ask you to keep in mind our problem, namely, are the physical and mental characters of children correlated with their or their parents' environment to a higher, an equal, or a lesser extent than they are correlated with their parents' physical and mental characters?

The larger series of statistics from Glasgow is 
not really so satisfactory as one might at first sight suppose, as it appears that comparatively few married women in Glasgow have other than the customary domestic work of their homes.

Dr Leslie Mackenzie, in his report on these statistics, divides the schools into four groups according to the districts in which the schools are situated, and we have kept to these groups in working out the correlation coefficients-but have also worked the coefficients for all schools taken together.

Group A comprises schools in the poorest districts of the city.

Group B comprises schools in poor districts.

Group C comprises schools in districts of a better class.

Group D comprises schools in districts of a still higher class, and includes four out of five Higher Grade Schools.

What then is the effect of the employment of the mother on the height and weight of her sons in Glasgow and in Edinburgh?

In the Introductory Note to the C.O.S. Report of the Edinburgh children it is stated that the children come from a school in the poorest part of the city, but that this school also has an admixture of the children of the comfortable and respectable working class.

Table I gives the correlation coefficients of the effect of the employment of mothers on the weight and height of their sons, and we notice :

(I) That the employment of mothers is cor- 
related to a small extent with lesser weight of their sons, the coefficient being 12 for all schools in Glasgow and 14 for Edinburgh, and we may say that the results obtained from the two distinct sets of statistics are well in agreement.

(2) That the employment of mothers is also correlated with lesser height of sons, and this correlation

TABLE I.

\begin{tabular}{|c|c|c|c|c|c|}
\hline \multicolumn{5}{|c|}{$\begin{array}{c}\text { Influence of the Employment of Mothers on the } \\
\text { Physique of her children }\end{array}$} & $\begin{array}{l}\text { Influence of } \\
\text { Heredity }\end{array}$ \\
\hline & \multicolumn{2}{|c|}{ Sons } & \multicolumn{2}{|c|}{ Daughters } & \\
\hline & IVeight & Height & Weight & Height & $\begin{array}{c}\text { Stature: Mother and } \\
\text { Son }\end{array}$ \\
\hline Glasgow & & & & & $\begin{array}{l}\text { Mother and } \\
\text { Daughter } \\
5\end{array}$ \\
\hline 응 A & $\cdot 06$ & $\cdot$ I I & $?$ & $?$ & (2) \\
\hline 亏 $\mathrm{B}$ & $\cdot 12$ & $\cdot 15$ & $\cdot$ I I & ? & Eye-colour: Parental 49 \\
\hline$\div \mathrm{C}$ & 'I I & $\cdot 19$ & ' I I & $\circ$ & $\begin{array}{l}\text { Grand } \\
\text { Parental } 32\end{array}$ \\
\hline ปี $\mathrm{D}$ & .03 & $\stackrel{\cdot 17}{ }$ & .09 & 12 & Great \\
\hline All schools & $\cdot 12$ & $\cdot 20$ & $?$ & $?$ & $\begin{array}{ll} & \text { Grand } \\
" & \text { Parental }\end{array}$ \\
\hline Edinburgh & & & & & \\
\hline All schools & $\cdot 14$ & ०09 & $\cdot 02$ & '০০ & \\
\hline
\end{tabular}

is somewhat larger than that found for weight in Glasgow. The effect of the employment of mothers on the height of sons in Edinburgh is measured by the coefficient 09 , which is distinctly lower than that found for all Glasgow. The Edinburgh schools are, however, probably closest in grade to the Glasgow Group A. 
(3) That there is a distinct difference in the correlation coefficients in the different school groups in Glasgow. This is not what we should expect if the population were homogeneous, and leads one to think that some special influence must be at work which has lowered the correlation in the worst school group or raised it in the better school groups. Taking into consideration the value found for the Edinburgh schools I should be inclined to think that the factor we have not yet measured is one that has artificially raised the coefficient in the better school groups.

We must next compare the influence of the employment of the mother on the physique of her son with the hereditary influence of the actual height of the mother on the height of her son. This hereditary influence is given in Table I for the sake of comparison. The effect of inheritance of stature of mother and son is measured by the coefficient 49 . The coefficients for eye-colour for the parental, grand parental, and great grand parental relationships are also given, and it will be noticed that the only value at all comparable with the environmental values is that found for great grand parents, which is about equal to that found for the effect of mothers' employment on sons' height in Glasgow, but distinctly higher than the other correlation coefficients. We cannot help being struck by the comparative unimportance of, at any rate, one environmental factor as compared with the heredity factor.

I will add one further remark on the differences we have found in the correlations between employment 
of the mother and height of her sons in Glasgow. In Glasgow the values found range from ' $I$ to 2 . At present I have no final explanation beyond heterogeneity for this result. But I would mention a fact noted by $\mathrm{Mr}$ Tocher in a paper on a pigmentation survey of Scotland, published recently in Biometrika. In that paper $\mathrm{Mr}$ Tocher calls attention to the large foreign element in Glasgow as judged by the names of the children and confirmed by their hair and eye-colour. There are a large number of Jews, especially in Groups B and C, and a fairly large proportion of Irish in the schools in Group D. Can mixture of races account for the higher correlations in some of the Glasgow groups ${ }^{1}$ ?

Future investigations will show whether the influence of the mother's employment on the height of her sons is greater than (as apparently in Glasgow) or less than (as apparently in Edinburgh) the influence of her employment on the weight, and whether the influence of employment on height is represented by the higher or lower correlation coefficient, by 2 or by 'I. At present I must content myself with saying that the connection between the employment of the mother and the weight of her sons is about $\cdot 12$, and that the connection between the employment of the mother and the height of her sons is between 'I and 2 . Taking into consideration the result found in the worst school

1 If we compare the mean height and weight of the Edinburgh boys with those of boys in the different school groups at Glasgow, we find that they lie between the Glasgow groups A and B, just where the correlation coefficients fall. Thus the Edinburgh and Glasgow values may not be really contradictory. 
group I am inclined to think that the lower value is the more correct.

Even if the higher value proves to be the true one, 20 is still a low correlation, and when we remember that the value for the correlation coefficient of heredity between height of mother and son is 49 we see that employment of the mother has far less influence than heredity on the physique of the son.

Unfortunately I have not yet found the correlation between the employment of the mother and the height and weight of her children for all school groups in Glasgow but I have worked out the results for two school groups and for the Edinburgh children. In the Edinburgh schools we see that there is practically no connection between employment of the mother and the physique of her children; the correlation coefficients are ${ }^{\circ} \mathrm{O} 2$ and $\mathrm{O}$. When we examine the results for Glasgow we see that the effect of the mother's employment on the weight of her daughters is very uniform in the three school groups, ' I I, 'I I and '09, and is about the same as the effect on the weight of the sons, though higher in the best group of schools. The two height results are again more irregular; it would seem that the height of girls is less affected by the mother's employment than the height of boys, and in one of the two school groups it is not affected at all which agrees with the results found for Edinburgh.

The results we have reached so far show on the whole that the employment of the mother has even less influence on the physique of her daughters than on the physique of her sons. 
Employment of the mothers then is associated to a small extent with lighter weight and shorter stature of their sons, but I am not sure that even the small association we find is necessarily a true measure of cause and effect. There are secondary obscuring effects of heredity. The weaker and more delicate mothers may not seek external employment, and naturally they would have weaker children. This lowers the association. Furthermore, inferior physique in the fathers may be a reason for the necessity of the mother's work. This would raise the association. We know from the C.O.S. report that the mother's work is associated with a lower rate of wage of the father-the average wage of the husband of an unemployed woman is $26 s$. $2 d$. and of an employed woman is $22 s$. I $1 d$. It seems reasonable to suppose that a man of inferior physique may have to take a lower wage, and thus it is his wife who will be obliged to work. Now if the husbands of these working women are physically weaker than other husbands we should expect their sons to be shorter and lighter than other persons' sons, whether the mother worked or not. We want to know the height and weight of the husbands of employed and unemployed mothers before we can be sure what proportion of the correlation we see between the mother's employment and son's height and weight is due actually to the mother's work and what is really due to the less weight and height of the fathers. I quite realize that we may find low wages do not depend on the physique of a workman at all, but, if they do, then some of the apparent 
result on the child of the mother's work will probably be due to the inferior physique of her husband.

There is another point in this connection I should like to mention. If employment of mothers has a bad effect on their sons, either directly before birth or indirectly owing to less home care, there ought to be less bad effect when the mother only works out part of the day than when she works out the whole of the day; but this is not the case, at least it is not the case in Edinburgh in those families investi gated by the C.O.S. From this report we are able to divide the mothers into four classes: (I) those who do no work beyond their domestic duties, (2) those who work in their homes, (3) those who work out part of their time, (4) those who work out the whole of their time. The diagram shows the

Weight of Boys at a Constant Age.

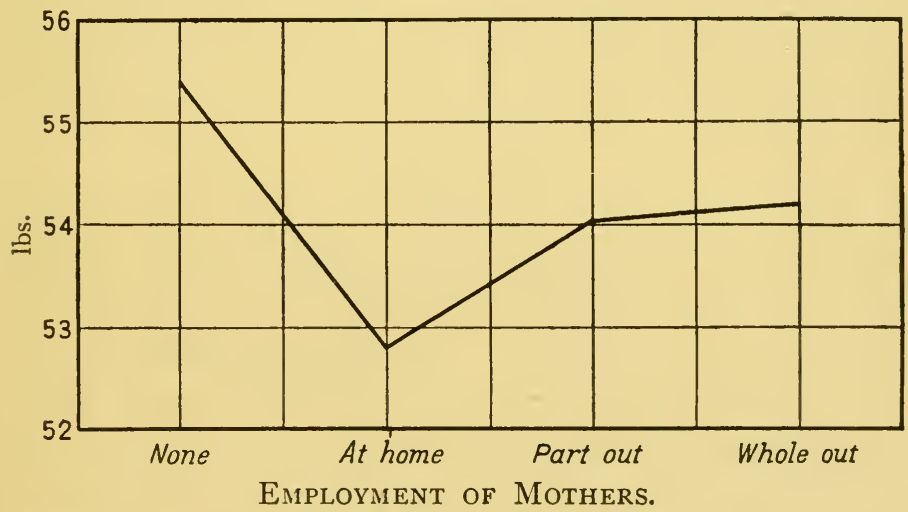

average weight of the boys for a constant age, i.e. the mean age 9.6 years. The mean weight of the boys is practically identical whether the mother works out all or only part of the time.

When the mother works "in" the weight of the boys is lowest, but there are only $3 \mathrm{I}$ cases, so we 
can lay no stress on this result; the mother works out part of the time in I29, and the whole time in 79 cases, which are more reasonable numbers on which to base a conclusion.

We must now turn to the second problem under consideration, i.e. the influence of the occupation of the father on the physique of his sons. Unhealthy trades have been considered largely responsible for physical unfitness in the children. After some consideration we decided to measure the unhealthiness of a trade by the annual deathrate per rooo living in the different trades between the ages 25 and 45 . These numbers were taken from the Registrar General's returns for Scotland, and range from 3 per thousand for ministers and gamekeepers to 18 per thousand among barmen, cellarmen and general labourers. The classification is not by any means perfect but, though rough, it gives a fairly satisfactory estimate of the healthiness or unhealthiness of a trade.

\section{TABLE II.}

Low Mortality Rate of Fathers and Greater Height AND WEIGHT OF SONS.

\begin{tabular}{|c|c|c|c|}
\hline & & & Influence of Heredity \\
\hline Schools & Weight & Height & Stature \\
\hline A & •09 & $\cdot 12$ & \multirow{4}{*}{$\begin{array}{l}\text { Father and }{ }_{51} \\
\text { Son } \\
\begin{array}{l}\text { Father and } \\
\text { Daughter }\end{array}{ }^{\prime} \text { I }\end{array}$} \\
\hline $\mathrm{B}$ & .04 & .07 & \\
\hline C & .03 & .05 & \\
\hline $\mathrm{D}$ & 'OI & $\circ 2$ & \\
\hline All & .09 & 12 & \\
\hline
\end{tabular}


Here the results are very regular and practically the same for height and weight. There is a certain very slight association between the unhealthy trade of a father, as measured by the mortality rate, and inferior physique in his children in the worst school group, but it becomes practically nil in the better school groups. We must again notice the low value of the correlation coefficient when we compare it with the value found for the correlation between height of father and son. And in this case also I must point out that we do not know how much of this apparent association is due indirectly to heredity, and to the probable fact that on the whole weaklings are driven into less desirable occupations. A man who is physically unfit has to work for any employer who will take him, and we shall probably frequently find him doing casual labour or working in a factory where little bodily strength is required. Here again we need the average height and weight of the fathers of all these sons to see whether fathers in a trade with a low mortality rate are taller and heavier than fathers in a trade with a high mortality rate. Is the casual labourer with a mortality rate of I 8 per thousand lighter and shorter than the carter with a mortality rate of 8 per thousand? the factory hand with a mortality rate of 13 per thousand than the blacksmith with a mortality rate of 7 per thousand? If so, children of the casual labourer or the factory hand will be lighter and shorter than the children of the carter or blacksmith, quite apart from any direct influence of unhealthy employment.

In the Appendix to the Report of the Royal 
Commission on Physical Training a table is given showing the average stature of men at all ages, divided into four classes according to their occupations. These do not correspond exactly with our mortality rates, but they do so roughly and are therefore of interest.

Class I includes farmers, clergy, lawyers, doctors, teachers, architects, \&c.; all these have a mortality rate of between 3 and 6 per 1000 and come in our mortality groups 3, 4, 5 and 6, except doctors, who are in our group 9.

Class II includes law clerks, shop-keepers, dealers in drugs, books, food, drinks, \&c., and the majority come in our mortality groups 7 and 8 .

Class III includes gardeners, railway and quarry workers, sailors, miners, \&c. ; these also are mostly included in the groups with mortality rates 7 and 8 but they vary more than Class II. The mortality rates of Classes II and III are, however, very similar.

Class IV includes workers in metal and stone, engravers, printers, \&c. who are mostly included in the groups with mortality rates 9 and $\mathrm{I}$.

The mortality rates then roughly correspond with these classes-- that is to say-

Class I includes occupations with the lowest mortality rates 3 and 6 .

Classes II and III include occupations with higher mortality rates 7 and 8 .

Class IV includes occupations with still higher rates 9 and $\mathrm{I} O$. 
The next table gives the mean height and weight for each class.

TABLE III.

\begin{tabular}{|c|c|c|c|c|}
\hline & Class I & Class II & Class III & Class IV \\
\hline Height & $69^{\circ} 4$ ins. & 67.9 & $67 \cdot 5$ & $66 \cdot 7$ \\
\hline Weight & $168.4 \mathrm{lbs}$. & $157^{\circ} \mathrm{O}$ & $157^{\circ} 5$ & $147^{\circ} 9$ \\
\hline
\end{tabular}

We see then that men occupied in a trade with a lower mortality rate are heavier and taller than men in a trade with a higher mortality rate, which suggests that the very small correlation we have found between unhealthiness of the father's trade and the height and weight of his sons is not all due to the unhealthiness of the trade, but is due at least, in part, to the inferior physique of the father. In fact I have very little hesitation in saying that unhealthiness of a trade of a father has small influence on the physique of his sons, and that it is because men of inferior physique are forced into worse trades that we see this apparent slight connection.

I will now turn to the question of drink and measure its effect on the height, weight, general health and intelligence of the children. I suppose more disastrous results have been attributed to drink than to any other social evil-I might almost say than to all other social evils taken together. Since we have been working at this subject I have read carefully many speeches, as reported in the papers, on the subject of drink, and confess I have been somewhat astonished at the statements occasionally made. 
For example: a well-known man is reported to have said in the course of a speech enumerating the various evils resulting from drink that $10 \%$ of the children of drunkards are tuberculous, but he made no mention of the fact that practically $10 \%$ of the general population suffer at one or another period from tuberculosis.

I do not say that alcoholism and tuberculosis are not associated, it is quite possible they may be, but a statement such as that I have quoted proves nothing of the sort, and is entirely misleading unless we are told at the same time the percentage of the tuberculous in the same class of the general population, which in this case was not stated.

We have two series of statistics for studying the question of the effect of drink, the Edinburgh Charity Organization Society Report and the statistics provided for us by Miss Dendy.

We will consider first the results obtained from the Edinburgh statistics, which are given in the next table.

TABLE IV.

\begin{tabular}{|l|c|c|c|}
\hline & $\begin{array}{c}\text { Drink and } \\
\text { Weight }\end{array}$ & $\begin{array}{c}\text { Drink and } \\
\text { Height }\end{array}$ & $\begin{array}{c}\text { Drink and } \\
\text { Intelligence }\end{array}$ \\
\hline Boys & 05 & $\circ 4$ & $-\cdot 03$ \\
Girls & $\circ 08$ & $\circ$ & $\circ 0$ \\
\hline
\end{tabular}

Here we see that drink in the parents has no effect on the intelligence of boys or girls, and practically none on the height and weight of boys. In the case 
of girls there is a very slight correlation between drinking of the parents and lower weight and height in the daughters, but considering that the probable error is $0_{3}$ the results are only just significant. Is this slight difference between the effect of drink on boys and girls due to the possibility that when the mother drinks the girls have to look after the home, whereas the responsibilities of the boys are not increased? But, whatever the reason, I would emphasize the fact that a correlation of ${ }^{\circ} \mathrm{O} 9$ is of very little importance as compared with a correlation of 50 due to heredity.

Before considering these results further we may turn to the statistics obtained from the special schools in Manchester. Here we cannot find the correlation coefficients between drink and actual height and weight of the children, but we can find the coefficient of correlation between drink and general health, and between drink and intelligence. In this case I have worked out the influence of the drinking of (I) the father, (2) the mother, on the health and intelligence of the children.

TABLE V.

\begin{tabular}{|l|c|c|c|c|}
\hline & \multicolumn{2}{|c|}{ Father } & \multicolumn{2}{|c|}{ Mother } \\
\cline { 2 - 4 } & $\begin{array}{c}\text { Intemperance } \\
\text { and } \\
\text { Health }\end{array}$ & $\begin{array}{c}\text { Intemperance } \\
\text { and } \\
\text { Intelligence }\end{array}$ & $\begin{array}{c}\text { Intemperance } \\
\text { and } \\
\text { Health }\end{array}$ & $\begin{array}{c}\text { Intemperance } \\
\text { and } \\
\text { Intelligence }\end{array}$ \\
\hline Sons & -.06 & $-\cdot$ I I & $-\cdot 07$ & 0I \\
Daughters & -04 & -.02 & $-\cdot 03$ & $-\cdot 08$ \\
\hline
\end{tabular}


Here again we see that drink has practically no influence on general health and intelligence of boys and girls, and the little influence it has is in favour of the children of drinking parents, they are healthier and more intelligent. These results are certainly startling and rather upset one's preconceived ideas, but it is perhaps a consolation that to the obvious and visible miseries of the children arising from drink, lowered intelligence and physique are not added.

But before asserting that intemperance of the parents has practically no effect on the physique and intelligence of the children, there is a point to be considered which I mentioned in the first part of this paper. What is the status of the drinking workman? Is the drinker on an average the abler man and of finer physique? If so, his children should show greater ability and better physique than the children of the non-drinking parent, and further, if the abler workman get higher wages, and thus notwithstanding drink, the food at home has been of better quality, we should expect his children to be better developed physically than those of the non-drinker.

As before the only estimate we have at present of the intelligence and physique of a workman is the wage he earns. A high wage on an average will mean a stronger and more efficient workman. We want to discover therefore whether drink and good wage go together to any large extent. If they do, then drinking fathers should have stronger and more intelligent children than non-drinking fathers. But 
unless there is a fairly well marked correlation it will not be sufficient to affect our results greatly.

I divided parents into three classes: ( I) both parents drink, (2) one parent drinks, (3) neither parent drinks, and the wages into four groups: (I) under I $8 s$. a week, (2) $18 s .-24 s$. inclusive, (3) $26 s$. to $34 s .$, (4) $36 s$. and over $36 s$. The correlation coefficient found by the fourfold method between the drinking of one or both parents and a high wage is ${ }^{\circ} 3$, which means that there is practically no connection between drinking of the parents and a high wage. The means show the same thing-the mean wage when both parents drink is $24 s .8 d$., when one parent drinks is $25 s .6 d$., and when neither parent drinks is $25 \mathrm{~s}$. $5 \mathrm{~d}$.- there is a slightly lower wage when both parents drink and a very slightly higher when one parent drinks, but we cannot attach any importance to a difference of $i d$. I tried to find from the Manchester special schools what was the connection between wages and drink, but the wages are very seldom given when the father drinks. From the few cases where they are given I found the average wage of a drinking father to be $23 s .7 d$., and of a non-drinking father to be $23 s$. $4 d$, i.e. a slightly higher wage for the drinking father in Manchester, but the numbers are too few for the results to be considered of much importance. If wage then is an estimate of ability and physique we may say that the ability and physique of the drinking workman is about the average, and we can state with greater confidence that the "well-known fact" that drinking has a bad 
effect on the physique and intelligence of the children has yet to be proved.

The whole subject of the influence of environment, owing to its complexity, is a fascinating one, partly because we are only just beginning to apply modern statistical methods to this side of eugenics, and the results we obtain are often very unexpected, perhaps we may say wholly contrary to current belief.

The fact that our conclusions as to the comparative unimportance of the environment factors of employment of mothers, occupation of fathers and drink of the parents are contrary to preconceived opinions, makes more work and more statistics on this side of eugenics most necessary.

We now come to the last point under consideration-the effect of the home environment on the intelligence, eyesight, glands and hearing of the children. The statistics being taken from the C.O.S. Report. The home environment factors we have chosen are:

(a) The number of people per room of the home. Unfortunately we do not know the size of the rooms, but in a general way we have a measure of the space in the home by considering the number of people per room.

(b) Economic condition of the home. We divided the homes into "good" and "bad" from a consideration of the information given in the C.O.S. "Summary of Facts," and took into account also the cleanliness of the children, regularity of attendance, \&c. 
(c) Physical condition of the parents. The Report states if the parents are broken down in health or suffer from tuberculosis, \&c., persistent alcoholism was included in bad physique.

(d) Moral condition of the parents. The chief difficulty was to decide how far alcoholism is to be treated as a moral complaint.

Generally speaking we placed the heavy drinker in the category of moral failure when the drinking was accompanied by "conviction for brutal assault on wife," "house a regular brothel," frequent convictions for being drunk and disorderly. Drinking is so prevalent that it is impossible to take it as determining in itself bad moral conditions. "Man a good workman, but goes on spree from time to time, is in two thrift clubs and attends church," or "old soldier and widower who takes a nip now and then, but is good to his girls-very nice, tidy, clean people," can hardly suffice for placing the described in the category of moral failure. On the other hand "Very dirty, untidy home... Man teetotal, keeps well at his work...China and clothes lying piled about room, thick with dust; air very bad. Children sickly (eldest imbecile); wife a slattern," seems to be a case where there is a moral deficiency likely to affect the condition of the children.

In each case we have had to trust to personal judgment, and though I think we should put the bulk of the cases in the same classes if we went through the book a second time, it is possible that in some doubtful cases our judgment would not be the same. The negative sign when it occurs means 
that the worse environment is associated with a better condition in the children.

Let us consider the results collected in Table VI.

\section{TABLE VI.}

Effect of Home Environment on Sight, Intelligence, GLaNDS, HEARING.

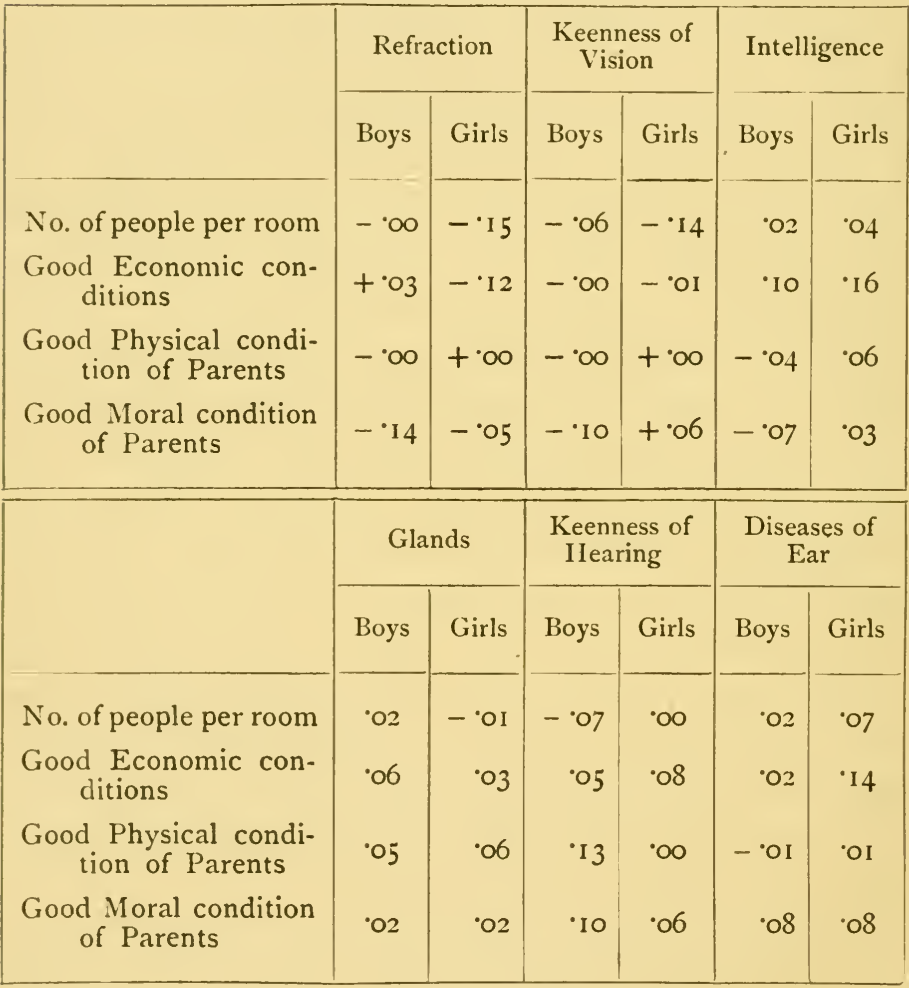

The eyesight results are already published in a memoir by Miss Barrington and Prof. Pearson. Normal vision is on the whole slightly associated with overcrowding, bad economic conditions and 
morally defective parentage. Can it be that these home conditions keep the children in the streets, and so relatively away from bad environment and in relatively fresher air? Whatever may be the cause the Edinburgh statistics show that the effect of home influence is not one-tenth that of heredity, and what exists, if it is appreciable at all, is in the opposite direction from what we should have anticipated. Intelligence is slightly associated with few people per room and with a good economic condition in the home for boys and girls, though for boys it is scarcely appreciable ; it is also associated for girls very slightly with good physical and moral condition in the parents, but for boys we get better intelligence in the children associated with bad physical and moral condition in the parents.

Glands and hearing tell the same tale. There is only a slight connection between the presence of swollen glands or bad hearing and bad environmental conditions. All the coefficients are small and irrregular, some scarcely appreciable, but in most cases they are positive, i.e. better physique goes with better environment, though it is but in a weak degree ${ }^{1}$.

Such a table as that on p. 30, indicating in many directions the relative insignificance of nurture in

1 Heredity as before plays far the larger part. The measure of the inheritance of eyesight is equal to that found for other physical characters and the same is true of intelligence (49). Recent work of the Laboratory (British Medical Journal, July, 1909: see Appendix to this Lecture) shows that environmental conditions can hardly be the chief source of eye-disease. The correlations are low and more often negative than in the case of ear-disease. 
influencing man's welfare, gives us reason to pause when we consider the methods of modern social reform.

The question of the respective influences of heredity and environment is becoming one of vital importance. It seems only too true at the present time that the physically and mentally weaker stocks are reproducing themselves at a greater rate than those of sounder physique and intelligence.

This, unchanged, must mean that the average physique and ability of our nation as a whole will decline and must decline unless we can prove that by a better environment we can raise the level of the community. So far as our investigations have gone at present they show clearly the small influence of environment; work of the mother, an unhealthy trade of the father and the drinking of the parents seem to have very little influence on the physique of the children. Overcrowding, bad economic conditions, bad physical and moral conditions of the parents have practically no effect on the intelligence, eyesight, glands and hearing of the children. It is possible that better measurements of environmental characters than we yet possess may show more correlation, and it is also possible that other characters may prove more influential. But so far as our researches reach I think we have shown that it is quite easy to demonstrate a large hereditary factor, and it is not at all an easy thing to show that any of the environmental factors we have measured up to the present time have any important effect on the children. Not only are the correlations low but we 
have reason to think that such small correlations as exist may be secondary results of racial or hereditary influences.

Practically all social legislation has been based on the assumption that better environment meant race progress, whereas the link between the two is probably that a genuine race progress will result in a better environment. The views of philanthropists and of those who insist that the race can be substantially bettered by changed environment appeal to our sympathies, but these reformers have yet to prove their creed. So far as our investigations have gone they show that improvement in social conditions will not compensate for a bad hereditary influence; the problem of physical and mental degeneration cannot be solved by preventing mothers from working, by closing public-houses, or by erecting model dwellings. The only way to keep a nation strong mentally and physically is to see to it that each new generation is derived chiefly from the fitter members of the generation before. 


\section{APPENDIX $A^{1}$.}

\section{HOME CONIITIONS AND EYESIGHT.}

By Karl Pearson, F.R.S.

IT may not be without interest, in view of recent criticisms of a memoir by Miss Barrington and myself ${ }^{2}$, to publish some further determinations of the relation of home conditions to sight.

Before doing so it will be well to point out one or two important considerations which I think have considerable bearing on the manner in which statistics ought to be collected, having regard to the medical inspection of school children, which is now becoming universal.

The first point I would insist upon is that careful distinction must be made between $(a)$ home environment and $(b)$ school environment.

Our paper dealt chiefly with the influence of home environment on both refraction and acuity of vision. Now, as far as I am aware, the only material hitherto available for testing the influence of the actual home conditions on the presence of eye disease, on the goodness or badness of vision, or on shortsightedness, is that provided by the report of the Edinburgh Charity Organization Committee, where we have for the first time the sociological report on the home conditions placed alongside the ophthalmological report on the child's eyes, and accompanied in each case by the age of the child. I do not see how it is possible without such information to draw conclusions as to whether the home conditions do or do not affect sight. I am quite prepared to be shown that the conditions in Edinburgh are exceptional, but the proof can only be given when the children who are reported

1 Reprinted by kind permission from the British Medical Journal, July 17,1909 .

2 Eugenics Laboratory Memoirs, v. "A First Study of Vision and of the Relative Influence of Heredity and Environment on Sight." Dulau and Co. 1909. 
on elsewhere are followed up into their homes, and the state of these is recorded, as in the Edinburgh investigation.

Further, the Edinburgh material was of special value, because there is not the same extraordinary mixture of racial types in that city which is to be found in Glasgow or London. We are told, for example, that Russian Jews have in London a very high percentage of eye defect. Any one who has studied the copious statistics of Randal must be convinced that the degree and extent of myopia is markedly a racial character ${ }^{1}$. Those who have investigated any local group in this country know that in anthropometric characters it is usually significantly differentiated from any other local group. The population of our suburbs is usually more sedentary than the population in the working class districts of the town itself and less mixed.

I know, as a matter of fact, that the cephalic index of school children varies very sensibly from one district of London to a second. On this ground alone it is not possible, without control measurements, to assert that, because the percentage of eye defect varies from Whitechapel to Hampstead, the result is due to home environment. It may be so, but a mere statement of percentages in different districts without (a) age distributions, (b) racial proportions, and (c) percentages of defective parents in each district, will not convince those who desire logical statistical proof before forming any conclusion. It is well known that the defective parents also gravitate to the worst districts, and we may expect the defective children there also. For these reasons the work at Edinburgh was especially valuable. It gave age distribution, it dealt with a racially fairly homogeneous material, and it followed up the children into their homes and told us something, if not all we might desire to know, about their parents. I see no other way in which a real solution could be obtained for London. An individual school or two must have all-not only the defective-children examined, and the eyesight report must be accompanied by a sociological report.

A report such as that of Dr A. Hugh Thompson on the London school children, in which the numbers at each age of both the normal and the defective children are not given, cannot help the statistician in the least to arrive at definite results. Nor, unless the children are followed into their own homes, is it even possible to say how far bad

1 The Jews, like the Germans, are largely brachycephalic, and the increasing brachycephaly of the town populations is a point not without suggestiveness for changes in eyesight. 
food, bad air, or parental neglect may account for the presence of any disease. There is always the diathesis as a contributory source, and the fact that all the children in the same family may not be attacked, shows that the variability within the family also plays its part.

Again my critics will, I hope, pardon me if I say that I am not convinced when I am asked whether this or that "is not a fact." For example, that it is a fact that in the better homes the children are more studious, or that the more respectable parents keep their children at home. Either may be the truth, but what we want are actual numerical measures of the effect of these supposed causes in invalidating the apparently small influence of the environmental as compared with the hereditary factor.

What we want are more data before we conclude that results are paradoxes because of such or such an explanation being "a fact" or "a matter of common experience."

Let us attempt to get any information we can on the problem of whether the better class parents keep their children at home, and so their offspring are more studious and suffer more from myopia 1 . Now, I know of no statistics which at all touch this point of the studious character of the offspring of better class parents, but I suppose the argument to be that the children are kept more at close work and that this damages their sight. Now, it would be possible to compare the sight of children of the same age who came to school at different ages originally, and thus find out whether those who began to read earlier have markedly worse sight. It would be very desirable to collect statistics de novo on this point. The only material that I know of bearing on the subject is that used by Miss Barrington and myself, and provided by Cohn, who gives the correlation tables of sight and years of school life, and sight and age. We have shown that the relationship is more intimate between sight and age than between sight and years of school life, and that, considering the high correlation of years of school life and years of age, the latter is most probably only a derived result of the former. Now, we have recently re-worked Cohn's data and discovered the correlation between the ages at which the child began to read and the degree of myopia at a constant age. The partial correlation co-efficient is :

$0.0_{4}$, if age and length of school life have a correlation of 0.8 $0^{\circ}{ }_{3}$, if age and length of school life have a correlation of $0^{\circ} 9$.

1 The reader of our memoir will remember that our conclusion was, not that the better homes produced more myopia, but that there was no marked relationship between bad homes and defective sight. 
Now it will, perhaps, be said that the latter is a quite sensible correlation, but compare it with the heredity correlation of 0.40 to 0.60 , and we see that environment is quite overmastered by heredity. Furthermore, the correlation is the wrong way, the later the child went to school, the worse at a given age is the myopia. I have little doubt that the correlation in this case is sensibly zero, or the age at starting reading has little influence on the result. Cohn's statistics are, of course, not final, but they are very suggestive, because they have hitherto been supposed to prove the exact reverse of what is really extractable from them.

I now turn to the question of the effect of good or bad home environment on disease of the eye. I will consider first corneal nebula and illustrate by some of the percentages :

\begin{tabular}{|c|c|c|c|c|}
\hline \multirow{2}{*}{ Feature of the Home Estimated } & \multicolumn{2}{|c|}{ Boys } & \multicolumn{2}{|c|}{ Girls } \\
\hline & Good & $\mathrm{Bad}$ & Good & $\mathrm{Bad}$ \\
\hline Economic condition & $3 \cdot 6$ & $2 \cdot 3$ & 39 & 2.2 \\
\hline Overcrowding .................. & 2.5 & $3 \cdot 3$ & $2 \cdot 5$ & $3+$ \\
\hline Physical state of parents........... & $3^{\cdot 8}$ & $2 \cdot 5$ & $3 \cdot I$ & $2 \cdot 8$ \\
\hline${ }^{1}$ Moral state of parents $\ldots \ldots \ldots \ldots \ldots$ & 3.5 & $2 \cdot 5$ & $2 \cdot 5$ & 3.5 \\
\hline Means...... & 3.35 & $2 \cdot 65$ & $3 \cdot 00$ & 3.00 \\
\hline
\end{tabular}

Now it is extraordinarily difficult to lay any stress on results whose differences are of this order. A bad moral state of parents would be interpreted to mean less corneal nebula for the boys and more for the girls, the percentages being just reversed. Good economic conditions in both boys and girls would mean 1.5 per cent. more of the disease, and so would the good physical condition of the parents. In such circumstances what stress can be laid on the 0.8 per cent. difference between crowded and non-crowded homes? The only safe conclusion to be drawn is that in Edinburgh at least there is no marked relationship between corneal nebula and bad home environment. The curious point is that if we take all diseases of the

1 This category should $a$ priori be considered the most important one in this matter. It marks essentially neglect of the children. Where the home is practically a brothel or the parents habitual drunkards there can be no proper cleanliness or care of offspring. 
eye and eyelid, we appear to get a slightly more definite, but still a quite negligible relation between disease and home environment. A difficulty is whether to include strabismus or not; the correlations have been worked out by Miss E. M. Elderton, of the Eugenics Laboratory; including and excluding "squint." In each a positive correlation means that there is more eye disease with the worse home condition.

\begin{tabular}{|c|c|c|c|c|}
\hline \multirow{2}{*}{ Feature of the Home Estimated } & \multicolumn{2}{|c|}{ Boys } & \multicolumn{2}{|c|}{ Girls } \\
\hline & $\begin{array}{l}\text { With } \\
\text { Squint }\end{array}$ & $\begin{array}{l}\text { With- } \\
\text { out }\end{array}$ & $\begin{array}{l}\text { With } \\
\text { Squint }\end{array}$ & $\begin{array}{l}\text { With- } \\
\text { out }\end{array}$ \\
\hline Economic conditions ...... & 0.10 & 0.14 & -0.03 & 0.02 \\
\hline Overcrowding ................. & 0.05 & 0.08 & 0.04 & 0.12 \\
\hline Physical state of parents............ & -0.02 & -0.02 & -0.10 & $-0 \cdot 15$ \\
\hline Moral state of parents.... & 0.04 & 0.03 & -0.01 & 0.01 \\
\hline
\end{tabular}

Now, it is quite impossible to lay any stress on these results. Six out of the 16 show less disease with worse home conditions, and if we have positive correlations of 0.10 and $0^{\circ} 14$, we have negatives of $-0^{\circ} 10$ and -0.15 . Further, no correlation of this kind lying under about 0.25 can be really considered to have definite importance. How very different these values are from the values running from 0.4 to 0.6 found in our memoir for the inheritance factor!

It is worth while putting on record here the quantitative contributions of refraction and diseases of the eye in producing defective vision. The refraction results are taken from our memoir; the disease results have been recently worked out by Miss Elderton.

\begin{tabular}{|c|c|c|c|}
\hline & $\begin{array}{c}\text { Keenness of Vision } \\
\text { and Refraction } \\
\text { (Contingency) }\end{array}$ & \multicolumn{2}{|c|}{ Keenness of Vision and Disease } \\
& & Squint included & Without squint \\
\hline Boys ..... & $0 \cdot 58$ & $0 \cdot 36$ & $0 \cdot 2$ I \\
Girls ...... & $0 \cdot 54$ & $0 \cdot 50$ & $0 \cdot 32$ \\
\hline
\end{tabular}

It will be seen that, if we exclude strabismus, the diseases of eye and eyelid do not produce half the effect on vision that refraction does. 
Now I do not intend to argue for a moment that the Edinburgh data provide the final word in these matters, but they form the first solid attempt to provide information as to the influence of home environment. Neither the school medical officer nor, as a rule, the teacher can follow the children into their homes. All that has hitherto been done has been more or less plausible guesswork as to the relation of home environment to the health and intelligence of the child. I shall not be surprised to find, when further data are available, that the nation has for years been putting its money on "Environment" when "Heredity" wins in a canter. To say this is not to discourage all attempts to better defective sight in the schools or to check the intensification of myopia. But it would be foolish-in face of our increasing degeneracy-to neglect the possibility that only other methods can in the long run hinder the spread of defects. Better qualities, such as keen and strong vision, are no longer an absolute requisite for survival, and defectiveness, instead of meeting the stern judgment of Nature, is by governmental and charitable agencies supported to multiply its kind. The curative art in its tenderness for the individual may be disastrous for the race, unless it realizes fully the relative biological importance of heredity and environment.

\section{APPENDIX B.}

\section{CLEANLINESS AND VISION.}

Through the courtesy of Dr F. E. Rock, School Medical Officer of the Edmonton Education Committee, I have received data connecting the age, acuity of vision, and cleanliness of body and clothing of 953 Edmonton children. Statistically the data are somewhat erratic as there has been an age selection in testing the eyesight and clearly home environment, if we are to measure that by cleanliness of body and clothing, also produces an age selection. Dr Rock, as many another medical officer, not unnaturally, takes this cleanliness as the only measure available of home environment. Remembering what children are and will do, I must submit that it can never replace actually study of the homes and the parents. Taking it, however, as 
a measure of home environment, Dr Alice Lee provides me with the following correlations :

Age and acuity of vision $-\cdot 037$

(i.e. the vision is slightly worse for the elder children).

Age and home environment $+\circ 029$

(i.e. the cleanliness is slightly better with the elder children).

Acuity of vision and home environment +.072 .

Hence the relation between goodness of vision and home environment for a constant age $=073$, or, the relationship between home environment, as measured by cleanliness of body and clothing, and goodness of vision is just about one-seventh of the intensity of the relationship between goodness of vision in parent and child. Nor are we sure that the home environment is the source of this small correlation; for not only do the statistics indicate a marked selection of the ages and the homes, but degeneracy in the parents, which is usually characterised by defective vision among other factors, may be the source of the want of cleanliness; and the association of this with bad vision be thus only a secondary hereditary effect. Until we know far better than we do at present the closeness of correlation between various physical degeneracies and the relation of these in the parent to the home environment, it seems hardly possible to determine whether these small correlations are really the expression of nurture, or only a secondary effect of nature. What is certain is that they are practically negligible compared with the direct effect of nature.

K. P. 
UNIVERSITY OF LONDON

UNIVERSITY COLLEGE

\section{Biometric Laboratory}

DRAPERS' COMPANY RESEARCH MEMOIRS Biometric Series.

I. Mathematical Contributions to the Theory of Evolution. -XIII. On the Theory of Contingency and its Relation to Association and Normal Correlation. By KARL PEARSON, F.R.S. Issued. Price $4 s$.

II. Mathematical Contributions to the Theory of Evolution. -XIV. On the Theory of Skew Correlation and Non-linear Regression. By KARL PEARSON, F.R.S. Issued. Price 5s.

III. Mathematical Contributions to the Theory of Evolution. -XV. On the Mathematical Theory of Random Migration. By KARL PEARSON, F.R.S., with the assistance of JOHN BLAKEMAN, M.Sc. Issued. Price $5 s$.

IV. Mathematical Contributions to the Theory of Evolution. -XVI. On Further Methods of Measuring Correlation. By KARL PEARSON, F.R.S. Issued. Price $4 s$.

V. Mathematical Contributions to the Theory of Evolution. -XVII. On Homotyposis in the Animal Kingdom. By Ernest Warren, D.Sc, Alice LEe, D.Sc., EDNA LEA-Smith, MARION RAdFord, and KARL PEARSON, F.R.S.

Shortly.

VI. Albinism in Man. By Karl Pearson, E. NetTleSHIP, and C. H. USHER.

[At Press.

\section{Studies in National Deterioration.}

I. On the Relation of Fertility in Man to Social Status, and on the changes in this Relation that have taken place in the last 50 years. By DAvid Heron, M.A. Issued. Price 3 s.

II. A First Study of the Statistics of Pulmonary Tuberculosis (Inheritance). By KARL PEARSON, F.R.S. Issued. Price 3 s.

III. A Second Study of the Statistics of Pulmonary Tuberculosis, Marital Infection. By ERNEST G. POPE, revised by KARL PEAliSON, F R.S. With an Appendix on Assortative Mating by ETHEL M. ELDERToN. Issued. Price $3 s$.

IV. The Health of the School-Child in relation to its Mental Characters. BY KARL PEARSON, F.R.S. [Shortly.

The above may be obtaind from Dulau and Co., 37, Soho Square, London, $W$. 


\section{Engenics $\mathcal{L} a b o r a t o r y ~ \mathbb{P} u b l i c a t i o n s$}

DULAU \& CO., 37, SOHO SQUARE, LONDON, IV.

MEMOIR SERIES.

I. The Inheritance of Ability. By EDGAR SCHUSTER, M.A., D.Sc., First Galton Research Fellow, and Ethel M. Elderton, Galton Scholar. Issued. Price 4s.

II. A First Study of the Statistics of Insanity and the Inheritance of the Insane Diathesis. By DAviD Heron, M.A., Second Galton Research Fellow. Issued. Price 3 s.

1II. The Promise of Youth and the Performance of Manhood. By EdGar Schuster, M.A., D.Sc., First Galton Research Fellow. Issued. Price 2s. $6 d$.

IV. On the Measure of the Resemblance of First Cousins. By EThel M. Elderton, Galton Research Scholar, assisted by KARL PEARSON, F.R.S. Issued. Price 3 s. $6 d$.

V. A First Study of the Inheritance of Vision and of the Relative Influence of Heredity and Environment on Sight. By AMY BARRIngton, Galton Laboratory, and KARL PEARSON, F.R.S. Issued. Price 4s.

VI. The Treasury of Human Inheritance (Pedigrees of physical, psychical, and pathological Characters in Man). Parts I and II (double part). (Diabetes insipidus, Split-Foot, Polydactylism, Brachydactylism, Tuberculosis, Deaf-Mutism, Ability.) Issued by the Galton Laboratory. Price I 4 s.

VII. Influence of Parental Occupation and Habit on the Welfare of the Offspring. By ETHEL M. ELDERTON.

[Shortly.

VIII. Influence of Unfavourable-Home Environment and Defective Physique on the Intelligence of School Children. By DAvid HERON, M.A.

[Shortly.

IX. The Treasury of Human Inheritance (Pedigrees of physical, psychical and pathological Characters in Man). Part III (Angioneurotic Oedema, Hermaphroditism, Deaf-Mutism, Insanity, Commercial Ability). Issued by the Galton Laboratory. Price $6 s$. 

Date Due

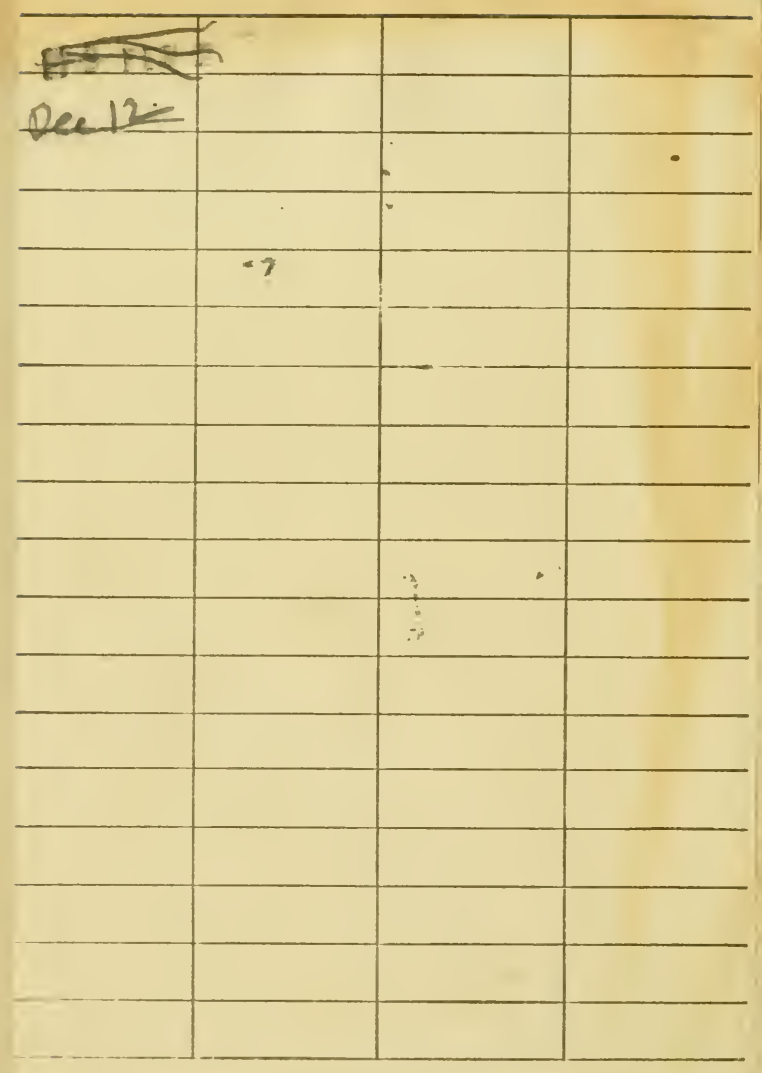

L. B. CAT. NO. 1137 
Science HQ 750.A1 L7 3

Elderton, Ethel Mary.

The relative strength of nurture and nature 


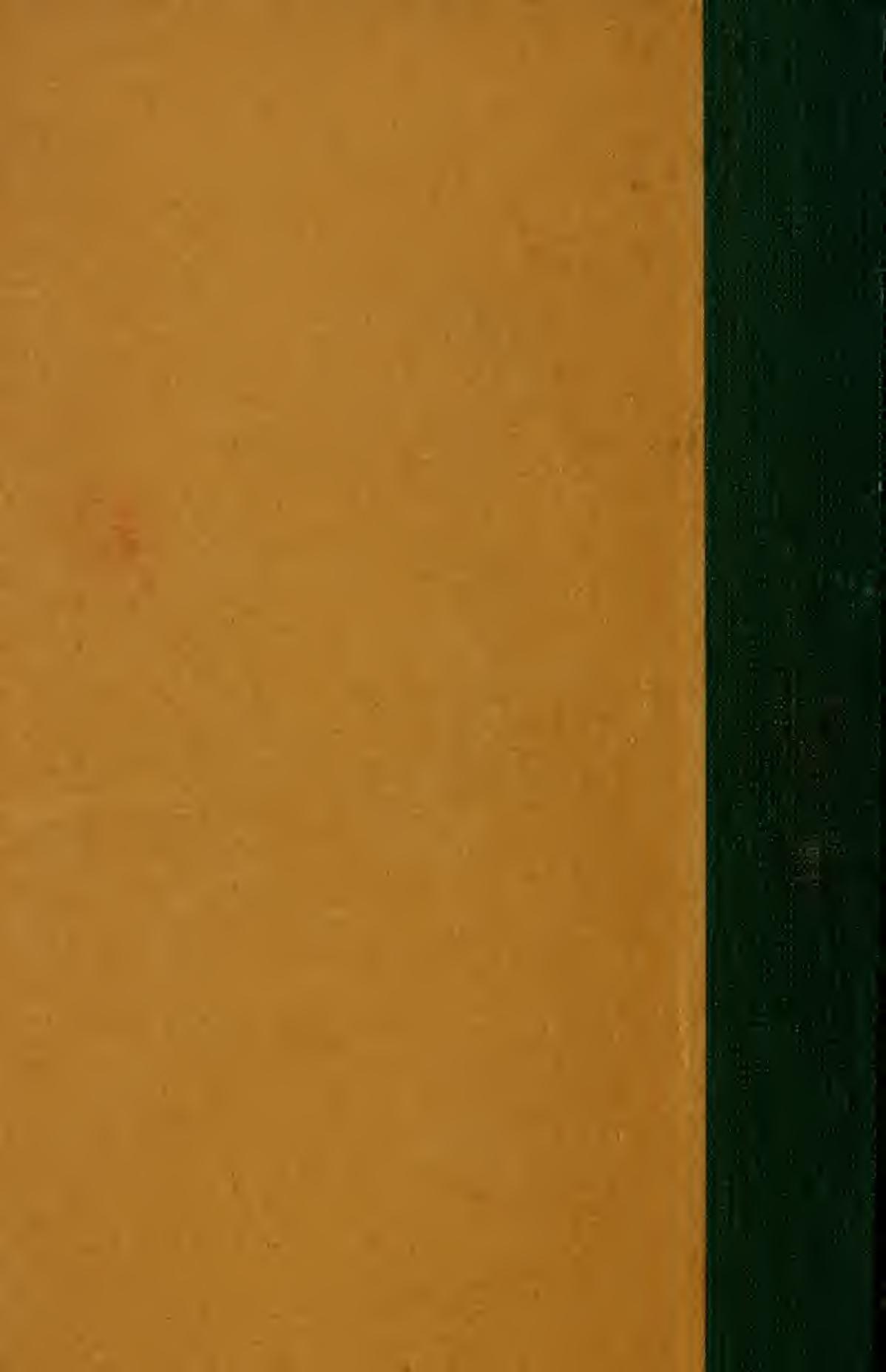

